\title{
Territorial Resilience: Toward a Proactive Meaning for Spatial Planning
}

\author{
Grazia Brunetta ${ }^{1}$, Rosario Ceravolo ${ }^{2}$, Carlo Alberto Barbieri ${ }^{1}$, Alberto Borghini ${ }^{1}$, \\ Francesca de Carlo ${ }^{1}$, Alfredo Mela ${ }^{1}$, Silvia Beltramo ${ }^{1}$, Andrea Longhi ${ }^{1}$, Giulia De Lucia ${ }^{2}$, \\ Stefano Ferraris ${ }^{3}$, Alessandro Pezzoli ${ }^{1}$, Carlotta Quagliolo ${ }^{1}$, Stefano Salata ${ }^{1, *(1)}$ \\ and Angioletta Voghera ${ }^{1}$
}

1 Responsible Risk Resilience Centre, Interuniversity Department of Regional and Urban Studies and Planning, Politecnico di Torino, 10125 Torino, Italy; grazia.brunetta@polito.it (G.B.); carloalberto.barbieri@polito.it (C.A.B.); alberto.borghini@polito.it (A.B.); francesca.decarlo@polito.it (F.d.C.); alfredo.mela@polito.it (A.M.); silvia.beltramo@polito.it (S.B.); andrea.longhi@polito.it (A.L.); alessandro.pezzoli@polito.it (A.P.); carlotta.quagliolo@polito.it (C.Q.); angioletta.voghera@polito.it (A.V.)

2 Responsible Risk Resilience Centre, Department of Structural, Geotechnical and Building Engineering, Politecnico di Torino, 10129 Torino, Italy; rosario.ceravolo@polito.it (R.C.); giulia.delucia@polito.it (G.D.L.)

3 Responsible Risk Resilience Centre, Interuniversity Department of Regional and Urban Studies and Planning, Università Degli Studi di Torino, 10124 Torino, Italy; stefano.ferraris@polito.it

* Correspondence: Stefano.salata@polito.it; Tel.: +39-011-090-7475

Received: 20 December 2018; Accepted: 13 April 2019; Published: 16 April 2019

\begin{abstract}
The international debate on resilience has grown around the ability of a community to prepare for and adapt to natural disasters, with a growing interest in holistically understanding complex systems. Although the concept of resilience has been investigated from different perspectives, the lack of understanding of its conceptual comprehensive aspects presents strong limitations for spatial planning and for the adoption of policies and programs for its measurement and achievement. In this paper, we refer to "territorial resilience" as an emerging concept capable of aiding the decision-making process of identifying vulnerabilities and improving the transformation of socio-ecological and technological systems (SETSs). Here, we explore the epistemology of resilience, reviewing the origins and the evolution of this term, providing evidence on how this conceptual umbrella is used by different disciplines to tackle problem-solving that arises from disaster management and command-control practices to augment the robustness. Assuming the SETSs paradigm, the seismic and structural engineering, social sciences and history, urban planning and climatology perspectives intersects providing different analytical levels of resilience, including vulnerability and patrimony from a community and cultural perspective. We conclude that territorial resilience surpasses the analytical barriers between different disciplines, providing a useful concept related to complex problem-solving phenomena for land use planning, opening a new research question: how can territorial resilience be measured, acknowledging different units and levels of analysis aiding decision-making in spatial plans and projects? In attempting to understand a resilient system, quantitative and qualitative measurements are crucial to supporting planning decisions.
\end{abstract}

Keywords: resilience; spatial planning; interdisciplinary; co-evolution; adaptation; transformation

\section{Introduction}

Climate change affects the well-being and the security of populations at a global scale, limiting the capacity of communities to resist and adapt to natural hazards and shocks. Many studies are investigating the relationship among resilience and some key concepts that are typically present in 
the climate change literature: vulnerability, sustainability, adaptation and transition [1-3]. Among these, resilience refers to the capacity of socio-ecological and technological systems (SETSs) to cope with shocks, providing a conceptual umbrella under which different disciplines tackle complex problems with holistic interventions [4].

Assuming the resilience definition provided by the Intergovernmental Panel on Climate Change Sixth Assessment Report (2019) — “the ability of a system to absorb disturbance preserving the same functioning structure, the capacity of self-organization and adapt to stress and change" [5] — an evident connection emerges with a definition of ecological sciences that opens to a wider interpretation of overcoming the current command-control adaptation policies addressed to specific climatic risks.

Adaptation and transformations to climate change scenarios involves responses that produce nonlinear changes in the system; therefore, addressing the root causes of risks is crucial to applying planning strategies. The main effect of climate change in urban areas is the variation in the precipitation system, which has increased the number of adverse events in the last years. The hydrological cycle is characterized by enormous temporal and spatial variability, which often generates critical situations for cities and the natural environment. Certain precipitation events, such as rain and snow, clearly show this variability. Therefore, the study and management of the hydrological cycle has become one of the main issues in resilience planning.

Traditionally, one of the most efficient measures against urban flooding is to increase the porous surfaces through urban planning and urban design solutions aimed at improving the resilience of the system. Such an approach could be defined as "predict and prevent," since it is mainly based on forecasting (through times series and projection of future climate trends), which allows the identification of policies for prevention. Nonetheless, not only transient shocks lead to the destabilization of the system but also chronic stress and slow changing conditions can play an important role [6]. Thus resilience design needs flexible adaptation overcoming the limited capacity to forecast events and assuming a non-linear and complex dynamics view of the systems that ranges from the adaptive socio-ecological transition to robust socio-technological solutions.

We explored the concept of resilience trying to answer the question if territorial resilience is useful for policy creation and decision-making during urban planning. To do so, we present how resilience has been defined and the relationship between different disciplinary perspectives [7]. The aim of this work was not to present a middle-term interpretation of territorial resilience that arises from a literature review, since this approach is currently too ambiguous: this understanding of resilience is still unwieldy to operationalize for planning [6]. We aimed at understanding what kind of relationships and how multiple definitions should be evaluated for normative interpretation, useful for defining strategies and territorial policies that enforce the response capacity, the preparedness and the evolution of territorial systems.

Particular attention was paid to the patrimony approach to resilience, since this analytical level is fruitful to shift from risk-based approaches grounded in robust command-control to adaptive strategies that leads to identify the vulnerable dimension of SETSs. Here we assume that territorial resilience emerges as a normative concept, whereas its assessment is still rooted in different analytical fields. At the base of this conceptual framework is the assumption that territorial strategies for adaptation and transformation require an in-depth assessment of the relationships between socio-ecological and socio-technical systems, bridging the barriers between the traditional robustness/techno-centric practices and the non-linear, uncertain and co-evolutive patterns that characterize the relation between society and nature [8].

The focus is on the role of territorial resilience in designing and projecting recovery practices, considering that the term "resilience" in ecological theory is the ability of the system to absorb changes or shocks from a disturbance while maintaining its internal relationship [9].

In this view, this paper presents a preliminary epistemological research activity completed by the Responsible Risk Resilience Centre (R3C) research group of Politecnico di Torino. The manuscript is the first output of the project "Defining Resilience" initiated in early 2018, which aims to develop 
an operational definition of territorial resilience. The R3C Project aims at design and operationalize an interdisciplinary research methodology to implement resilience in regional and urban systems. The project has been used to set up an in-depth discussion around the epistemological knowledge of Resilience by different theoretical scientific approaches and their practical applications through the operational research carried out by urban and regional planners, social scientists, anthropologists, engineers, historicist and ecologists.

\section{Definition of Resilience: from Seismic Engineers to Socio-Ecological and Technological Systems}

The word resilience, which originates from the Latin meaning of "jump" or "rebound," includes the physical concept of elastic return and restart in the opposite direction, as in a rising trajectory. From the structural engineering perspective, resilience, here intended as the mechanical property of a material, is represented by the pendulum test-machine invented by the French engineer Georges Augustin Albert Charpy and is defined by the work required to break a sample of a specific material with a single impact [10].

The opposite of the resilience index is the fragility index, by which a material is defined as the response to an applied force in a material. Any reference to perfect elasticity disappears [11], as the Charpy pendulum measures the dissipation of energy in the fractured surface.

Resilience is therefore considered as resistance to impulsive, brutal and rapid solicitations and differs from the resistance to the long-term application of forces that generate obsolescence, erosion, delamination or stress, which are considered cyclic actions.

In the specific field of seismic engineering, there are two parallel and sometimes concurrent concepts of resilience. The first is defined as physical ductility, which is the capacity of a material or a structure to yield without relevant increase of load. This definition is still rooted in the concept of energy dissipation and is considered the reciprocal to brittleness by seismic engineers [12]. The second is resistance, which is the degree to which a material opposes adverse forces [13]. The best anti-seismic strategy is not resistance but ductility, which is the capacity to deform with the dissipation of energy. Ductility is more than the ability to resist to long-term or acute forces, because plasticization is a permanent deformation that leads to another state of the material, augmenting its adaptive capacity and its ability to dissipate energy. However, that adaptive ability is limited.

Examples of this limit are well-represented from the socio-psychological perspective, where the resilience of a community is defined as the capability to positively react to shocks or persistent adverse factors. This perspective surpasses the mechanical concept of resistance to an event because the consequences of damages have, for the most part, an irreversible effect, forcing the community to a change [14,15].

From this viewpoint, resilience is an adaptation to new conditions and mobilizes endogenous and exogenous resources to reach a new level of functioning [16], sometimes producing better conditions. Analogously, from the engineering perspective, plasticization represents a change of state that corresponds to a new form of adaptation.

The process of plasticization introduced an emerging concept of modelling resilience, which is the stability of the system. The dynamic equilibrium of a system under perturbation can be stable, unstable or indifferent and this dynamic is similar to that of landscape ecology or social psychology. The stability is often connected to the maintenance of the fundamental characteristics of a system such as its functions, structure or identity [17]. It is then possible to define the resilience of a person, the housing system, the economy, institutions, natural environment and communities in general.

From the ecological point of view, resilience is persistence, adaptability and transformability of complex adaptive Socio Ecological Systems (SES), clarifying the dynamic and forward-looking nature of the concept [18]. In urban ecology, the resilience is the ability of urban systems to resist stress and absorb perturbations while conserving identity, structure and vital ecological processes [1]. A resilient urban system is composed of cyclical evolutionary phases: growth, specialization, collapse and reorganization. 
Similar to what has been theorized by Schumpeter for economical processes, the collapse determines the growth of a new economic system. This interpretation is also similar to landscape ecology theory for complex and adaptive systems [19], which is the concept of panarchy [20]. Panarchy defines the cycle of a system generating an upgrade or downgrade of the system itself. A resilient system is based on the adaptive capacity and the mutual interactions of all its components that create an innovation of the state.

This innovative capacity was extended to the study of SES [21] when the term resilience shifted from ecology to social sciences [22,23]. The socio-ecological school emphasizes renewal, reorganization, innovation, learning capacity and development using shocks as turning points from one state to another [2,24]. Particularly, innovation in SES refers to planning tools and practices leading to the introduction of a new emerging paradigm, including the capacity to assess and protect ecosystem services and related supporting, regulating, provisioning and cultural/aesthetic functions [25-27]. The ecosystem service approach aims at increasing the knowledge of SES to aid tin he decision-making process, preserving the natural capital and augmenting the capacity of the system to react under challenging phenomena (climate, environmental, socio-economic and technological), fostering dynamicity, flexibility and the superior adaptability of the system [28].

The difficult challenge is to transform urban systems into something not only robust to adverse shocks but also increasing the innovation, preparedness and co-evolving capacity that distinguish the anti-fragile system, preparing communities to face perturbations, uncertainties and unpredictability as components that generate changes and new conditions $[29,30]$. Therefore, urban planning is shifting its attention to new tools and instruments that are not focused on static resistance to adverse factors but on finding new adaptive and innovative solutions [24,31,32] that are able to transform the system, producing radical and nonlinear positive changes addressing multiple risks $[3,33]$. In this view, the recent paradigm introduced by the study of SETSs moves forward the general sustainable development approach of SES rooted in the "reductionist" theory with a limited capacity to co-evolve into new operational dimensions coming up with an integration of the technological sphere of SES $[6,34,35]$. SETSs lens might help to achieve a more comprehensive and holistic resilient strategy that helps urban planning to define priorities, areas of interventions, including both technological/infrastructural and Nature-Based solutions for the community.

\section{Multiple Interpretations of Resilience}

There is no internationally agreed upon definition of resilience [31]. Interpretations range from a critique of the term [36], the concept [37] and the metaphor [38]. Resilience is addressed as a "way of thinking" [39], a "performance" [40] or a "capacity" of a system [41]. The term offers as many interpretations as the different disciplinary perspectives applied to the concept. Some definitions that could be worth exploring are related to the following fields:

(1) Ecology: A measure of the persistence of systems and their ability to absorb change and disturbance while maintaining the same relationships between populations or state variables [9]. The capacity of a system to absorb disturbance and reorganize while undergoing change so as to essentially retain the same function, structure, identity and feedback [42].

(2) Urban Systems: The ability of an urban system and all its constituent socio-ecological and socio-technical networks across temporal and spatial scales, to maintain or rapidly return to desired functions in the face of a disturbance, to adapt to change and to quickly transform systems that limit current or future adaptive capacity [16].

(3) Logistics: The ability of a system to return to its original state or move to a new more desirable state after being disturbed [43].

(4) Engineering: The ability of systems to anticipate and adapt to the potential for surprise and failure [44]. An organization's ability to survive and potentially even thrive, in times of crisis [45]. 
Resilience can be analysed from different levels (individual, domestic, groupings, community and corporate) and from various components (building environment, economy and organizations, institutions and the natural environment) and there is no automatic correspondence among components or level. Each level affects the components in different ways.

For instance, the psychological and sociological literature that focuses on community-level resilience presents qualitative distinctions among the components: (1) the equity and distribution of economic resources [46,47]; (2) the quality of the network relationships of the community (participation, connection to places, community feeling, the ability to activate resources, etc.) [14,46]; (3) the expertise of community, such as the adaptability and creativity (political partnership, problem-solving ability, capacity to act as a community and so forth. [48,49]; and (4) communications and information, including shared narratives, responsible media rather than reliable information sources [46].

Other classifications assign more importance to value-based dimensions from political-institutional and socio-health aspects or the presence of services and infrastructure. The historical consideration concerning resilience, for example, outlined the role of the extension of common goods and their influence on social adaptation processes and culture [50,51].

From the perspective of cultural anthropology, resilience has a semiotic value that is intrinsically delivered by a message, a description or a representation. In this view, the landscape is the cultural message that is perceived and communicated by local communities. The cultural and linguistic dimension of resilience presents a more complex and intricate development when compared with the engineering interpretations: it is a complex dynamic process that leads the community to recognize its environment, acknowledging the memory and heritage of previous generations, enriching the present.

The multiplicity of interpretations has resulted in a flourishing use of this term for different purposes with some overlaps. In each definition, the metaphor of "rebound" or "return" to a new condition of "non-dynamic equilibrium" is envisaged. With some minor distinctions, interpretations poorly address the complex multiple relations between humans and their environment that should be considered during decision-making processes aimed at supporting land use planning. Alongside the socio-ecological perspective, the concept is often related to disaster preparedness, vulnerability or sustainable development [52] but the relationship between resilience and disaster preparedness or vulnerability remains unclear and the overlaps between resilience and sustainability creates misleading interpretations. Leaving apart the theoretical definition of sustainability and resilience, which differs a lot $[29,53]$ the SESs-perspective of sustainable planning has been largely addressed to the "reductionist" theory in the utilization of finite environmental goods (soil, air and water) leading to a traditional command-control (Socio-technical) practice based on single-risk assessment; while the SETSs-perspective offers a comprehensive dynamic view that is based upon the analysis of vulnerabilities, accepting the change of system and adapting to it (Table 1). This encourage planners to shift from the traditional risk-assessment engineering design for infrastructural interventions to a more comprehensive, flexible and socio-ecologically-based approach to the vulnerability of the entire system instead of the single component [6].

Table 1. The shifting approach to planning from SES to SETS perspective.

\begin{tabular}{cccc}
\hline Approach & Analytical Level & Analytical Structure & Dimension \\
\hline $\begin{array}{c}\text { Command-control } \\
\text { Co-evolution }\end{array}$ & Component & Risk/robustness & Socio-Technical \\
& System & Vulnerable/resilience & Socio-Ecological-Technical \\
\hline
\end{tabular}

The increasing number of studies that mixes sustainable and resilient approaches and solutions is counterproductive when territorial resilience is addressed with missing elements: dynamism, adaptation and learning capacity. As such, we aimed to share a common theoretical background around the concept of resilience, which is crucial to developing its practical implementation. 
It is possible to define a system as being intrinsically vulnerable to stress and shocks and minimally resilient, as defined by Folke [24]. In this sense, vulnerability is counterpoised to resilience, even if they act simultaneously. However, a significant difference exists between vulnerability and resilience: the first includes the exposure to a specific hazard, whereas the second emerges from the characteristics of a complex interaction between the system itself and the interaction between society and its governance. Resilience is more than just vulnerability, not only including the analysis of exposure to stress and shocks but also defining recovery and reorganization periods that includes the community and cultural instances hereafter considered the "patrimony" of urban systems. Nonetheless, the identification of vulnerabilities is an asset to define the kind of interventions essential to build resilience in each city [54].

Many recent studies focused on vulnerability and resilience evaluation of SETSs at the urban scale, including the economic assessment of multiple risks, proposing possible solutions and interventions to improve the resilience of territories. In this context, the flexibility of solutions available to an extended range of situations allows the rigorous selection of different kinds of interventions to face climate change conditions $[1,21,54]$.

In this view, Belcore et al. introduced an innovative index that quantifies the ability of a local system to react to hazard: the "Incapacity to React" is the interaction between vulnerability and resilience [55]. In this study, the interconnections between vulnerability and resilience to face climate change are addressed by an urban index that considers climate-driven shocks and their environmental, political and economic stresses. Urban resilience and adaptive politics are measured against a vast quantity of threats while addressing derived co-benefits [21,56]. Therefore, the concept of resilience includes a combination of hazard prediction and a combined analysis of the inducted risks posing particular emphasis on strengthening both urban infrastructure and Nature-Based Solutions [57,58] and the recovery speed of communities after natural and anthropic damages [1].

From an urban planning perspective, the growing interest in the SETSs approach has focused on the transition from a culture of emergency and reconstruction planning following the occurrence of a shock, to a comprehensive preventive-planned approach to the problem of vulnerability and multiple risks assessment [59]. The expectations of spatial planning are met by focusing on local problem-solving issues in dealing with uncertainty.

The dynamic and complex perspective offered by the SETSs approach places a particular significance on resilience for defining actions and priority of interventions to build a resilient landscape $[31,60,61]$. The cultural and community involvement is then fundamental for understand the specific characteristics of a place and its culture, tradition and legacy, while defining new strategies and policy, to achieve the resilience of the system. From this view, urban and territorial resilience are conceived as the co-evolutive property of a system, where more emphasis is placed upon urban planning anticipatory approaches, acknowledging pre-existing governance models and the historical interaction of communities and risks. Urban design tools are conceived using a map of urban vulnerabilities [62]. To do so, the co-evolutionary approach to resilience is significant for urban planning, since enables the integration of the engineering risk management approach with the interdisciplinary historical perspective.

\section{A Resilient System from the Co-Evolutive Perspective}

The dynamic non-equilibrium of a system is an opportunity to create knowledge and intelligence through learning capacity, robustness, adaptation and transformation [19,63]. Particularly, the adaptation of the system is the capacity to change, providing new answers to external stress. The perspective of dynamic co-evolution is an approach derived from social sciences [64], which considers the resilience of a complex system as an evolutionary process.

The evolutionary approach from a historical perspective is one of the most promising interdisciplinary research themes that is shifting the engineering risk management approach into a more holistic a comprehensive evolutionary interpretation of urban systems. Natural disasters affect millions of people annually, consuming huge amounts of financial resources dedicated to forecasting 
and early warning communication. However, the damages produced by natural hazards are still growing [65]. From a global climatic change perspective, risk governance is crucial to addressing future hazards.

Risk offers an un-deterministic interpretation that considers the role of individual and collective/strategic choices and the transformation of the policy framework. Conversely, urban and spatial planning do not include the uncertainty dimension, focusing instead on the achievement of a "final state of equilibrium." This approach is rooted in planning theories and their connected models of rationality, following the idea of rational urban development planning during the 20th century [66]. Ecological sciences and environmental approaches are based on non-static paradigms. Therefore, a rational comprehensive planning model and its operational application by plans and projects have been affected by a weak approach to inclusive, flexible and communicative strategic development that promotes integration, partnership, communication skill and the temporal dimension of processes [67].

The integration of co-evolution in planning is therefore crucial and is based on two emergent conditions: the preservation of memory and the evolution capacity considering robustness, adaptive ability and vulnerability reduction [68].

The aim that characterizes evolutionary planning is building adaptive governance of territories that emerges from social systems and communities through several initiatives of governmental agencies, international organizations and centres that promote politics and practices with incentives to reinforce the community role and the adaptive capacity of systems [69].

\subsection{Patrimony Approach from the Community Perspective}

The consideration of the evolutionary dimension is a key variable in understanding the interaction of limited social groups with their landscape [70].

SESTs are conceived emphasizing the adaptive, learning and self-organizing capacity of communities that are symbiotically connected with their natural and built environment. Therefore, the interaction of social systems with their environment is the basic condition of community resilience [71]. Such an interaction does not require a hierarchical relationship between the components (society, environment and infrastructures): SETSs are neither the socio-technical component of ecosystems, nor the natural environment of social groups and their settlements [72]. SETSs are complex systems where the integration between socio-technical and biophysical factors is mutual and flowing in a continuous process of adaptive co-evolution [53]. This is why co-evolution has emerged as the primary characteristic of a SETSs, leading to a new phase (post-disaster) that generates adaptive capacities favouring a positive or negative trend [73]. Hence, resilience should not be considered as a pre-defined characteristic of a system that generates fixed post-disaster scenarios. The evaluation of the coping and recovering capacities considers only factors external to the system (the problem of isolation of elements), whereas resilience is a process that depends on endogenous community resources [74].

Commonly, risk analysis is affected by the isolation of elements, which is an approach that considers a single-risk assessment or at least their sum, for a specific site. Such an approach dominates when resilience is operationalized in a methodological sequence for its practical measurement: the exogenous single-risk assessment defines a unique resilient model that can be replied according to pre-defined spatial determinants and temporal variables. Assuming this oversimplification, the result of a post-disaster situation is simplistically evaluated by an assessment of the pre-defined characteristics of some of the components of the system but this assumption neglects one of the most critical factors of community resilience: the political side of the recovering phase that distinguishes an emergency and the reconstruction period [75].

The process of resilience is more complex and requires a new point of view that considers the positive or negative feedback between the community [76], its heritage and the relationship with the environment. Feedback is a fundamental endogenous process that differentiates community resilience and enforces the capacity of a social group to react. From this view, cultural and natural 
heritage are pivotal to maintaining the memory of the community and its sense of belonging and therefore its maintenance or valuation deeply increases the cohesion and resilience of a community. In turn, cultural heritage is a resource that depends on the structural characteristics of settlements, their maintenance and their state of obsolescence; thus, structural resilience of buildings is based on the capacity to respect the traditional knowledge of manufacturing. The capacity to preserve the know-how, ordinary maintenance and approaches to protect cultural heritage depends on territorial governance, which leads to the possibility of increasing the intrinsic resilience of a system.

In a dynamic concept, the pre-existing disaster conditions are considerable resources since they contribute to defining community resilience. Community resilience is further conditioned by positive or negative feedback between communities and their environment after a disaster and during the recovering phases. This process can be divided into various stages (the temporal dimension of resilience). Khalili et al. distinguished the immediate and emergency phase and those of recovery, demonstrating that there is a sharp decrease in the well-being and the quality of life of the citizens in the first phase, while a slight increase in these conditions occurs in the second phase [77].

The phases mentioned above are divided into more detailed sub-phasing stages between the initial emergency phase (distinguished by the temporary living solutions, such as tents or hotels, for affected people) and the recovery phase, that could be subdivided into different re-organization categories until the reconstruction is completed. As an example, the post-disaster phase is subjected to oscillations between "heroic" phases (immediate reconstruction) then successive disillusion (when what initially imagined is not realized) rather than "give-up" phases [78].

The process of capturing resources for the population is subject to variations, meaning that it is impossible to exactly quantify the recovering capacity of a community when a disaster has not yet occurred. The adaptive capacity demonstrated during the heroic after-disaster phase is not the same capacity that could be employed in the long-term where better conditions are achieved with slow incremental improvements. It is possible that, after a low-resilient approach, a phase of the application of resources and energies follows through the intervention of facilitators [79], who are active citizens capable of stimulating and increasing the learning capacity of communities but without formal involvement by institutions.

The resilience from a community perspective is then affected by the difficulties that the people encounter during the recovery phase. Initially, resilience is characterized by the negative impact of a shock, whereas in the following stages, feedback between the people, the institutional capacity to recover, the learning capacity and the environment can favour different scenarios and the formation of "transitory communities" that may even be conflicting [80].

Placing resilience and vulnerabilities at the core of spatial dynamics avoids framing the communities affected by disasters as victims, providing instead an active view of its ability to recover and enter a new phase of development. Vulnerabilities and resilience are two key complementary factors that are strongly affected by the co-evolutive interaction between the community and its environment [2].

Even when endogenous resources are used to achieve a faster recovery, neither the institutional capacity to support reconstruction, nor the financial support will interact with the need of local communities to reconstruct their sense of belonging, their history or their cultural identity. Thus, resilience is not an auto-referential modality to react against shocks. When external resources are used to support the recovery phase, their use should be socially accepted by the community that has to receive the foreign contribution and the implementation of recovery actions should be negotiated [81].

\subsection{Patrimony Approach from the Cultural Perspective}

The landscape is not the result of an instant social process but is diachronically handed down: the landscape can be considered as the product of a message between the inhabitants who live in the places [82]. They, including the succession of generations in a specific place, receive their peculiarities from traditions and language. Consequently, the landscape gives the inhabitants both 
cultural and linguistic experiences that generate the "idea of landscape," which is the landscape itself [83]. Accordingly, the landscape or the idea of landscape, can be considered from two levels: a cultural experience (landscape communication) and a linguistic experience (landscape message). Both aspects are considered structural because the experience of a territory is sourced from these two aspects, which also influence their perceptions.

The landscape includes a cultural-heritage experience of the territory. The degradation of memory and the community identity-through the destruction of collective symbols and the loss of the sense of belonging produced by the cultural heritage-may also economically damage the community, for example, in terms of tourism reduction rather than other recreative or productive activities.

Some documents produced by international organisations highlight how the risk of damage to historic properties, cultural heritage sites, historic environment and historic landmarks related to anthropic activities and disasters, is highly threatening to cultural heritage. At the level of international institutions, a debate around the relationship between cultural heritage and resilience has opened $[84,85]$. The persistence of historic landmarks, linked to traditional values and activities in communities, handed down from generation to generation, have to be preserved and enhanced through specific conservation or valorisation projects. Currently, the consideration of cultural heritage during risk management programs and strategies is limited, especially with respect to the consequences of climate change. Weak awareness and cooperation between people who deal with risk management or with preservation and valorisation of cultural heritage sites, are evident. Heritage can be used as a pivotal element to improve social resilience. Even assuming this comprehensive perspective, some crucial questions remain un-answered: who has the role to decide what is (and what is not) "heritage" in terms of risk, rehabilitation and reconstruction? Can an ex-ante determination be assumed to be an objective of heritage? Are there common methods of cultural and historical assessment attributed to heritage or can they vary on the basis of the political and religious cultural context? These questions seem almost rhetoric for those who deal with heritage disciplines. However, the consideration of heritage in the processes of resilience includes its social construction: a process of collective consensus that surpasses the recognition of tangible objects and values [86-88].

Each heritage system is the result of selection, identification, classification and cataloguing processes that require an active role of subjects who experience the heritage. Despite objects having an intrinsic value, if the community does not recognise it, artefacts cannot be considered heritage.

From the heritage perspective, it is not possible to assume a static vision; a more processual dimension (co-evolution) view is required. In the case of interventions after disaster damage, the reconstruction has to be planned not only in order to recover a material object but also to create a new object providing heritage value - embedded in historical values-that will be shared and recognised. From this perspective, the awareness of the heritage risk has to include a responsible idea from both the people and communities about cultural, social, demographic, economic and religious transformations. Some concepts, such as the equilibrium of a system, are conceived as dynamic processes or the role of communities in the learning processes, which are shared by heritage and territorial cultural systems. This is why preservation activities aim at a continuous reinterpretation of the object and not at static material conservation.

Preservation is applied through a dynamic process to define new values allowing people to recognise the objects as heritage. From this view, the best preserved heritage is the one that incorporates, from a historical perspective, functional and structural resilience (here, intended as its cultural dimension). The ideological value of heritage is reflected in the adopted prevention policies that may guarantee satisfactory levels of protection against disasters.

The social memory of a community affected by disaster or unexpected calamities develops both from past experience and the collective decisions of the affected communities. Reconstruction after a disaster is a crucial time period because local stakeholders and institutional authorities decide which elements of cultural heritage are to be preserved, rebuilt or abandoned, sometimes through emotive impetus or previous incomplete evaluations. 
A resilient approach to damage generates several scenarios that are influenced by the perspective from which heritage is considered, whereas the political dimensions of these different processes are less evident and definable. A resilient community is able to accept heritage loss and simultaneously build new heritage by storing the memory of tragic events and understanding its dynamics and reasons.

\section{Discussion: Is Territorial Resilience an Emerging Approach for Spatial Planning?}

The community and cultural perspectives of resilience are based on the concept of dynamic non-equilibrium and the co-evolutionary characteristics of a SETSs [61]. Hence, resilience promotes changes in the policies and strategies of institutions, organizations and social networks [89,90] addressed by an interdisciplinary approach aimed at promoting the capacity of the modification and adaptation of the system [91]. This process arises through multi-level and multi-sectoral vision of the responsibility of adaptive and flexible governance and of planning solutions in a medium- and long-term perspective.

These properties are intrinsically assumed by the definition of SETSs where, resilience is the capacity of the system - and of all its socio-ecological, technical, infrastructural components-to preserve or rapidly return to basic functionalities, responding to turbulence and/or shocks, of adaptation to climate change, to transform the subset of components which limit the present and/or the future evolution capacity [92].

This definition clearly refers to resilience as a capacity to preserve and transform the system; therefore, resilience is a dynamic process. Viewing resilience as a process instead of a fixed condition is one of the main issues that emerges from the introduced interpretations: resilience is a challenge for urban planning and not a fixed attribute of the system.

Here, we assume that "territorial resilience" is an emerging concept capable of aiding with the decision-making process for identifying vulnerabilities and improving the transformation of socio-geographical areas [93]. We purpose to define territorial resilience as an "emerging concept" since the SETSs approach considers the dynamic non-linear interaction between the endogenous characters of the system and its exogenous transient shocks, chronic stresses and their sudden or slow changing conditions that affects both the patrimony and the governance system. In this view, urban planning is part of the resilience itself since it considers in a general an holistic view the SETSs by a normative and urban design perspective and therefore assumes the co-evolutionary vision of communities.

The question remains as to how to operationalize this concept in planning. Firstly, an uncertain future should be adequately considered. "What if" events should integrate spatial analysis that supports decision-making in land use planning using measuring methodologies that includes the sensitivity of the system to internal and external shocks and disturbances altering its properties in a mutual relation. The measurement of vulnerabilities grounded on the spatial knowledge of the system and its potential transformation should be capable of dialoguing with multi-risk assessment and climate modelling integrating the response capacities of the local governance and their feedbacks with community. This knowledge has to be developed by new geographic information systems that create local datasets to deliver spatial representations which accounts for socio-technical, environmental and economic components of the system. Secondly, aspects of patrimony should be adequately considered as most representative of the co-evolutive and evolving property of the system. This approach improves the awareness of cultural heritage as a useful tool to build resilient communities, reducing the effect of disasters due to natural and anthropic hazards that may affect cultural heritage by a coupling of infrastructure design focus resistant elements with more Nature-Based by "soft" actions. The inclusion of cultural heritage in disaster mitigation projects focuses on prevention instead of the reaction to disaster, which improves the relationship between protected sites and resilience by the role of heritage for communities.

The abovementioned two points distinguish territorial resilience as an approach that requires radical innovations in planning techniques and procedures.

The introduction of a multicriteria approach for spatial analysis is necessary in order to measure resilience as a complex phenomenon that moves from the traditional inquiry methods (on different 
scales and levels) to a comprehensive interpretation that assumes (1) a multidisciplinary view, (2) including the cultural and community dimension and considering (3) the phasing of time as a co-evolutive concept that produces evidence of the transition and change of the system along the path to recovery. Such a transition is necessary to design more flexible, diverse and ecologically based elements along with hard and resistant ones re-thinking both grey and green Infrastructures a product of the social-ecological and technological interaction that support the transition of the system. To do so, it is crucial to downscale and adapt existing frameworks to spatially measure the resilience of a system to suggest local interventions, policies and strategies. Some relevant experiences are already available and should be carefully considered. The Rockefeller Foundation's "100 Resilient Cities" programme aims to measure urban resilience working across government departments; the "Smart Mature Resilience" is a framework that directs all available resources toward well-defined goals, ensures transparency and the democratic principles of decision-making for city resilience development and planning. The Urban Resilience to Extremes Sustainability Research Network (UREx SRN) focuses on integrating social, ecological and technical systems to devise, analyse and support urban infrastructure decisions in the face of climatic uncertainty.

Such initiatives aim at better understand the link between theoretical knowledge of resilience and the definition of an operational urban planning operational model as a precondition for further research development. This, in order to support territorial decision-makers in developing and implementing resilience measures and transformation and adaptation strategies in cities. Other documents in the field of operational resilience promote the active knowledge of public administration and researchers. As an example, the policies against risks are an asset in the 2015-2030 European Roadmap for the implementation of the Sendai Framework implemented by Global Platform and Regional Platforms, which aims at stimulating the dialogue between public and private stakeholders to develop risk reduction and risk management agreements. Similarly, the guidelines of the European Forum for Disaster Risk Reduction (2017) include the request for all authorities to add the protection and enhancement of cultural heritage to disaster risk management policies and action [94]. The promotion of operational actions to prompt territorial resilience is the basis of the work completed by the Resilience Alliance, which is an international, multidisciplinary research organization that explores the dynamics of social-ecological systems and particularly work towards the goal of better understanding how the manage ecosystems.

The adaptation of these frameworks requires an in-depth knowledge of climate data and their temporal variations associated with a sound understanding of site conditions (land use, sealing, slopes and soil characteristics). Environmental and the disaster history may offer inputs to a wide periodization that simultaneously considers climate history and the history of institutions in charge for risk management $[95,96]$. As such, the relationship between urban heritage and urbanization displays a diachronic interpretation in the long-term.

Adaptation of general frameworks to local conditions is a process affected by (1) long-term elaboration using the process of spatial interpolation of data and (2) strong limitations due to the variability in the climatic context dependent on local and global variables, uncertainty and dynamism [54]. The predict and prevent approach may not consider indirect effects, such as systemic and institutional weakness, due to its limited capacity to find adaptive solutions to specific climate hazards $[49,54,97]$.

\section{Conclusions: An Operational Theory}

A theory that considers the co-evolutive dynamics of territorial resilience assumes the non-linear adaptive capacity of a system, which is influenced by phenomena that are difficult to measure: the spontaneous self-adaptation of a community in a specific environment. The relationship between the intention of a community and co-evolution [91] are key aspects of the concept of responsibility.

What emerges from the different disciplinary perspective is here synthetically reported: (1) the co-evolutive dimension as an essential component of the resilience; (2) the focus on changes instead of the state of the system as a condition to define resilience; (3) the evaluation 
of system's vulnerability by SETSs perspective; (4) the multidisciplinary integration of different fields of investigation to address resilience; and (5) the use of a mix of the quantitative and qualitative characteristics of the system to define resilient policies.

The debate on resilience has grown around the ability of a community to prepare and adapt to natural disasters, with a growing interest within many disciplines to holistically understand complex systems. The implementation of resilient strategies and tools from a land use planning perspective has largely remained confined to the single disciplinary perspective of different approaches and silo mentality with a weak inter-disciplinary coordination.

Land use planning is an activity derived by the long-term interaction among technical, political and civil needs that are considered in a decision-making process, intended as the arena of a complex negotiation between stakeholders [98,99]. During such interaction, the consultation of maps and technical documents is crucial to creating awareness of socio-economic vulnerabilities and their territorial distribution.

The definition of territorial resilience is intended here as an urban planning projectual concept with normative content [100] that is basically grounded in the operational integration of the vast quantity of information that frames the assessments that support land use planning project and strategies $[28,101,102]$.

This concept shifts the traditional urban planning governance approaches based on bureaucratic values, rationality and efficiency, leading to new adaptable and innovative frameworks [103]. Territorial resilience is an innovative concepts and contributes to closing the gap separating the theoretical knowledge of resilience from its translation into spatial plans and projects. Although traditionally resilience is characterized by the analytical levels of risk management and command-control practices the shift toward a comprehensive, flexible and socio-ecologically-based approach to the vulnerability of the entire system instead of the single component is necessary. This, in the view of presenting a spatial evaluation of the values that match the needs of urban planners and their capacity to align regulatory, fiscal and financial instruments to regulate land use [104]. This theoretical approach introduces a new research question: how to spatially assess territorial resilience acknowledging different units and levels of analysis aiding with decision-making in urban planning?

To answer this question, local resilience frameworks should develop an integrated vision that links together the knowledge of the system and its governance with political decision-making to improve the adaptation, transformation and learning capacity of the system. Within this background, the definition of a first theoretical framework is necessary to avoid un-coherent interpretations of territorial resilience.

The implementation of resilience in a territorial system is based on the reduction of vulnerability, the pursuit of social and institutional learning capacity and the achievement of better territorial governance that increase the adaptation ability and the reduce vulnerabilities.

From this view, resilience is not the result of a conventional top-down process but is rather the effect of a proactive vision of socio-political and community systems to implement collective and individual actions, fostering self-adapting, innovation, learning capacity and the evolution of the system. Therefore, these are key aspects to consider since resilience increases the chances of achieving a sustainable future within an unpredictable evolutionary perspective [105].

An assessment of resilience that assumes the theoretical background presented in this paper will help address new experimental and pioneer methodological approaches for urban planning. This multi-disciplinary approach should generate feedback between assessment and territorial government, indicating and selecting sites where specific actions of mitigation, adaptation, risk reduction or transformations should be implemented to reduce the vulnerability of the system.

Notably, at the international level, the recent attention to urban and territorial resilience has generated an operational capacity to influence policy-making phases when outlining strategies and tools and legal frameworks for land use planning. Thus, the definition and the epistemological meaning of resilience affect the future policy of territorial governments. 
Author Contributions: Conceptualization, writing-review and editing, G.B., S.S.; investigation and writing for "Introduction", R.C., C.A.B., G.B.; investigation and writing in the field of "Resilient environment and climate change", A.P., C.Q., S.F.; investigation and writing for "Resilience in co-evolutive perspective", A.B., F.d.C.; investigation and writing for "The temporal issue of territorial resilience: the communitarian perspective", A.M.; investigation and writing for "The temporal issue of territorial resilience: the heritage perspective", S.B., A.L., G.D.L., A.V.; “Discussion and Conclusions”, G.B., S.S.

Funding: This research received no external funding.

Acknowledgments: This manuscript is a product of the project "Defining Resilience" of the Responsible Risk Resilience Centre (R3C) of Politecnico di Torino (see http://www.r3c.polito.it/). R3C is the first Italian research centre with specific goals of promoting adaptive and resilient strategies to address natural- and human-related risks, ensuring the safety of territorial and cultural heritage.

Conflicts of Interest: The authors declare no conflict of interest.

\section{References}

1. Leichenko, R. Climate change and urban resilience. Curr. Opin. Environ. Sustain. 2011, 3, 164-168. [CrossRef]

2. Miller, F.; Osbahr, H.; Boyd, E.; Thomalla, F.; Bharwani, S.; Ziervogel, G.; Walker, B.; Birkmann, J.; van der Leeuw, S.; Rockström, J.; et al. Resilience and Vulnerability: Complementary or Conflicting Concepts? Ecol. Soc. 2010, 15, 1-11. [CrossRef]

3. Vogel, C.; Moser, S.C.; Kasperson, R.E.; Dabelko, G.D. Linking vulnerability, adaptation, and resilience science to practice: pathways, players, and partnerships. Glob. Environ. Chang. 2007, 17, 349-364. [CrossRef]

4. Levine, S. Assessing Resilience: Why Quantification Misses the Point; Humanitarian Policy Group Overseas Development Institute: London, UK, 2014.

5. $\quad$ Bernstein, L.; Bosch, P.; Canziani, O.; Chen, Z.; Christ, R.; Davidson, O.; Hare, W.; Huq, S.; Karoly, D.; Kattsov, V.; et al. Climate Change 2007: Synthesis Report. Contribution of Working Groups I, II and III to the Fourth Assessment Report of the Intergovernmental Panel on Climate Change; IPCC: Geneva, Switzerland, 2007.

6. Krumme, K. Sustainable Development and Social-Ecological-Technological Systems Sustainable Development and Social-Ecological-Technological Systems (SETS): Resilience as a Guiding Principle in the Urban-Industrial Nexus. J. Renew. Energy Sustain. Dev. 2016, 2, 70-90. [CrossRef]

7. Bollettino, V.; Alcayna, T.; Dy, P.; Vinck, P. Introduction to Socio-Ecological Resilience. Oxford Res. Encycl. Nat. Hazard Sci. 2017, 4. [CrossRef]

8. Mosammam, H.M.; Nia, J.T.; Khani, H.; Teymouri, A.; Kazemi, M. Monitoring land use change and measuring urban sprawl based on its spatial forms: The case of Qom city. Egypt. J. Remote Sens. Sp. Sci. 2016. [CrossRef]

9. Holling, C.S. Resilience and stability of Ecological Systems. Source Annu. Rev. Ecol. Syst. 1973, 4, 1-23. [CrossRef]

10. Bader, M.G.; Ellis, R.M. The effect of notches and specimen geometry on the pendulum impact strength of uniaxial cfrp. Composites 1974, 5, 253-258. [CrossRef]

11. Shin, S.; Lee, S.; Judi, D.R.; Parvania, M.; Goharian, E.; McPherson, T.; Burian, S.J. A systematic review of quantitative resilience measures for water infrastructure systems. Water (Switzerland) 2018, 10, 164. [CrossRef]

12. Alhaddad, M.S.; Wazira, K.M.; Al-Salloum, Y.A.; Abbas, H. Ductility damage indices based on seismic performance of RC frames. Soil Dyn. Earthq. Eng. 2015, 77, 226-237. [CrossRef]

13. Takagi, J.; Wada, A. Recent earthquakes and the need for a new philosophy for earthquake-resistant design. Soil Dyn. Earthq. Eng. 2019, 119, 499-507. [CrossRef]

14. Schwarz, A.M.; Béné, C.; Bennett, G.; Boso, D.; Hilly, Z.; Paul, C.; Posala, R.; Sibiti, S.; Andrew, N. Vulnerability and resilience of remote rural communities to shocks and global changes: Empirical analysis from Solomon Islands. Glob. Environ. Chang. 2011, 21, 1128-1140. [CrossRef]

15. Béné, C.; Al-Hassan, R.M.; Amarasinghe, O.; Fong, P.; Ocran, J.; Onumah, E.; Ratuniata, R.; Van Tuyen, T.; McGregor, J.A.; Mills, D.J. Is resilience socially constructed? Empirical evidence from Fiji, Ghana, Sri Lanka, and Vietnam. Glob. Environ. Chang. 2016, 38, 153-170. [CrossRef]

16. Meerow, S.; Newell, J.P. Urban resilience for whom, what, when, where, and why? Urban Geogr. 2016, 1-21. [CrossRef]

17. Batabyal, A.A.; Beladi, H. The stability of stochastic systems: The case of persistence and resilience. Math. Comput. Model. 1999, 30, 27-34. [CrossRef]

18. Folke, C. Resilience. Ecol. Soc. 2016, 21, 44. [CrossRef] 
19. Holing, C.S. Understanding the Complexity of Economic, Ecological, and Social Systems. Ecosystems 2001, 4, 390-405. [CrossRef]

20. Allen, C.R.; Angeler, D.G.; Garmestani, A.S.; Gunderson, L.H.; Holling, C.S. Panarchy: Theory and Application. Ecosystems 2014, 17, 578-589. [CrossRef]

21. Ernstson, H.; Der Leeuw, S.E.V.; Redman, C.L.; Meffert, D.J.; Davis, G.; Alfsen, C.; Elmqvist, T. Urban transitions: On urban resilience and human-dominated ecosystems. Ambio 2010, 39, 531-545. [CrossRef]

22. Adger, W.N. Social and ecological resilience: Are they related? Prog. Hum. Geogr. 2000, 24, 347-364. [CrossRef]

23. Turner, B.L.; Kasperson, R.E.; Matson, P.A.; Mccarthy, J.J.; Corell, R.W.; Christensen, L.; Eckley, N.; Kasperson, J.X.; Luers, A.; Martello, M.L.; et al. A framework for vulnerability analysis in sustainability science. Proc. Natl. Acad. Sci. USA 2003, 100, 8074-8079. [CrossRef]

24. Folke, C. Resilience: The emergence of a perspective for social-ecological systems analyses. Glob. Environ. Chang. 2006, 16, 253-267. [CrossRef]

25. Partidario, M.R.; Gomes, R.C. Ecosystem services inclusive strategic environmental assessment. Environ. Impact Assess. Rev. 2013, 40, 36-46. [CrossRef]

26. Haines-Young, R.; Potschin, M. Common International Classification of Ecosystem Services (CICES): Consultation on Version 4, August-December 2012; School of Geography, University of Nottingham: Nottingham, UK, 2013.

27. Maes, J.; Egoh, B.; Willemen, L.; Liquete, C.; Vihervaara, P.; Schägner, J.P.; Grizzetti, B.; Drakou, E.G.; La Notte, A.; Zulian, G.; et al. Mapping ecosystem services for policy support and decision making in the European Union. Ecosyst. Serv. 2012, 1, 31-39. [CrossRef]

28. Meerow, S.; Newell, J.P. Spatial planning for multifunctional green infrastructure: Growing resilience in Detroit. Landsc. Urban Plan. 2017, 159, 62-75. [CrossRef]

29. Brand, F.S.; Jax, K. Focusing the meaning(s) of resilience: Resilience as a descriptive concept and a boundary object. Ecol. Soc. 2007, 12. [CrossRef]

30. White, I.; O'Hare, P. From rhetoric to reality: Which resilience, why resilience, and whose resilience in spatial planning? Environ. Plan. C Gov. Policy 2014, 32, 934-950. [CrossRef]

31. Meerow, S.; Newell, J.P.; Stults, M. Defining urban resilience: A review. Landsc. Urban Plan. 2016, 147, $38-49$. [CrossRef]

32. OECD. Guidelines for Resilience Systems Analysis-How to Analyse Risk and Build a Roadmap to Resilience; OECD: Paris, France, 2014.

33. Welsh, M. Resilience and responsibility: Governing uncertainty in a complex world. Geogr. J. 2014, 180, 15-26. [CrossRef]

34. Mcphearson, T.; Pickett, S.T.; Grimm, N.B.; Niemelä, J.; Alberti, M.; Elmqvist, T.; Weber, C.; Haase, D.; Breuste, J.; Qureshi, S. Advancing Urban Ecology toward a Science of Cities. Bioscience 2016, 66, 198-212. [CrossRef]

35. Markolf, S.A.; Chester, M.V.; Eisenberg, D.A.; Iwaniec, D.M.; Davidson, C.I.; Zimmerman, R.; Miller, T.R.; Ruddell, B.L.; Chang, H. Interdependent Infrastructure as Linked Social, Ecological, and Technological Systems (SETSs) to Address Lock-in and Enhance Resilience. Earth's Future 2018, 6, 1638-1659. [CrossRef]

36. Bhamra, R.; Dani, S.; Burnard, K. Resilience: the concept, a literature review and future directions. Int. J. Prod. Res. 2011, 49, 5375-5393. [CrossRef]

37. Thorén, H.; Thore, H. Resilience as a Unifying Concept. Int. Stud. Philos. Sci. 2014, 28, 303-324. [CrossRef]

38. DeVerteuil, G.; Golubchikov, O. Can resilience be redeemed? City 2016, 20, 143-151. [CrossRef]

39. Graziano, P.; Rizzi, P. Science of the Total Environment Vulnerability and resilience in the local systems: The case of Italian provinces. Sci. Total Environ. 2016, 553, 211-222. [CrossRef] [PubMed]

40. Figueiredo, L.; Honiden, T.; Schumann, A. Indicators for Resilient Cities; OECD: Paris, France, 2018.

41. Bhoite, S.; Birtill, K.; Cook, S.; Diaz, S.; Evans, V.; Fernandez, A.; Laura, F.; Kernaghan, S.; Loiacono, A.; Morera, B.E.; et al. City Resilience Framework; The Rockefeller Foundation: London, UK, 2014.

42. Walker, B.; Holling, C.S.; Carpenter, S.R.; Kinzig, A. Resilience, Adaptability and Transformability in Social-ecological Systems. Ecol. Soc. 2004, 9, 1-9. [CrossRef]

43. Christopher, M.; Peck, H. Building the Resilient Supply Chain. Int. J. Logist. Manag. 2014, 15, 1-14. [CrossRef]

44. Hollnagel, E.; Woods, D.D.; Leveson, N.G. Resilience Engineering. Concepts and Precepts; Hollnagel, E., Woods, D.D., Leveson, N.G., Eds.; Aldershot: Ashgate, UK, 2006. 
45. Seville, E. Resilience: Great Concept... But What Does it Mean for Organizations? In US Council on Competitiveness Workshop, Risk and Resilience; University of Canterbury: Christchurch, New Zealand, 2008; Volume July, pp. 9-14.

46. Norris, F.H.; Stevens, S.P.; Pfefferbaum, B.; Wyche, K.F.; Pfefferbaum, R.L. Community resilience as a metaphor, theory, set of capacities, and strategy for disaster readiness. Am. J. Community Psychol. 2008, 41, 127-150. [CrossRef]

47. Schlör, H.; Venghaus, S.; Hake, J.F. The FEW-Nexus city index - Measuring urban resilience. Appl. Energy 2018, 210, 382-392. [CrossRef]

48. Caputo, S.; Caserio, M.; Coles, R.; Jankovic, L.; Gaterell, M.R. Urban resilience: two diverging interpretations. J. Urban. 2015, 8, 222-240. [CrossRef]

49. Schipper, E.L.F. Climate Change Adaptation and Development: Exploring the Linkages. Tyndall Cent. Clim. Chang. Res. Work. Pap. 2007, 107, 20. [CrossRef]

50. Van Bavel, B.; Curtis, D. Better Understanding Disasters by Better Using History: Systematically Using the Historical Record as One Way to Advance Research into Disasters. Int. J. Mass Emerg. Disasters 2016, 34, 143-169. [CrossRef]

51. Rao, H.; Greve, H.R. Disasters and Community Resilience: Spanish Flu and the Formation of Retail Cooperatives in Norway. Acad. Manag. J. 2018, 61, 5-25. [CrossRef]

52. Pelling, M.; Manuel-navarrete, D. From Resilience to Transformation: the Adaptive Cycle in Two Mexican Urban Centers. Ecol. Soc. 2011, 16, 11.

53. Redman, C.L. Should sustainability and resilience be combined or remain distinct pursuits? Ecol. Soc. 2014, 19. [CrossRef]

54. Tyler, S.; Moench, M. A framework for urban climate resilience. Clim. Dev. 2012, 4, 311-326. [CrossRef]

55. Belcore, E.; Calvo, A.; Canessa, C.; Pezzoli, A. A Methodology for the Vulnerability Analysis of the Climate Change in the Oromia Region, Ethiopia. In Renewing Local Planning to Face Climate Change in the Tropics.; Tiepolo, M., Pezzoli, A., Tarchiani, V., Eds.; Springer, Cambridge International Science Publishing: Great Abingdon, UK, 2017; pp. 73-102. ISBN 978-3-319-59095-0.

56. Wilbanks, T.J.; Kates, R.W. Beyond adapting to climate change: embedding adaptation in responses to multiple threats and stresses. Ann. Assoc. Am. Geogr. 2010, 100, 719-728. [CrossRef]

57. Grêt-Regamey, A.; Altwegg, J.; Sirén, E.A.; van Strien, M.J.; Weibel, B. Integrating ecosystem services into spatial planning-A spatial decision support tool. Landsc. Urban Plan. 2017, 165, 206-219. [CrossRef]

58. Burkhard, B.; Kroll, F.; Nedkov, S.; Müller, F. Mapping ecosystem service supply, demand and budgets. Ecol. Indic. 2012, 21, 17-29. [CrossRef]

59. Rizzi, P.; Graziano, P.; Dallara, A. A capacity approach to territorial resilience: the case of European regions. Ann. Reg. Sci. 2018, 60, 285-328. [CrossRef]

60. Artmann, M. Urban gray vs. urban green vs. soil protection-Development of a systemic solution to soil sealing management on the example of Germany. Environ. Impact Assess. Rev. 2016, 59, 27-42. [CrossRef]

61. Pickett, S.T.A.; Cadenasso, M.L.; Grove, J.M. Resilient cities: Meaning, models, and metaphor for integrating the ecological, socio-economic, and planning realms. Landsc. Urban Plan. 2004, 69, 369-384. [CrossRef]

62. Coaffee, J.; Therrien, M.-C.; Chelleri, L.; Henstra, D.; Aldrich, D.P.; Mitchell, C.L.; Tsenkova, S.; Rigaud, E. Urban resilience implementation: A policy challenge and research agenda for the 21st century. J. Conting. Cris. Manag. 2018, 403-410. [CrossRef]

63. Folke, C.; Carpenter, S.R.; Walker, B.; Scheffer, M.; Chapin, T.; Rockström, J. Resilience Thinking: Integrating Resilience, Adaptability and Transformability. Ecol. Soc. 2010, 15, 20. [CrossRef]

64. Portugali, J. Self-Organization and the City, 1st ed.; Springer: Berlin, Germany, 2000; ISBN 978-3-662-04099-7.

65. Mitchell, J.K. Megacities and natural disasters: A comparative analysis. GeoJournal 1999, 49, $137-142$. [CrossRef]

66. Mazza, L. Technical Knowledge and Planning Actions. Plan. Theory 2002, 1, 11-26. [CrossRef]

67. Alexander, E.R. Rationality Revisited: Planning Paradigms in a Post-Postmodernist Perspective. J. Plan. Educ. Res. 2000, 19, 242-256. [CrossRef]

68. Vale, L.J. The politics of resilient cities: Whose resilience and whose city? Build. Res. Inf. 2014, 42, $191-201$. [CrossRef] 
69. Moulaert, F.; Martinelli, F.; González, S.; Swyngedouw, E. Introduction: Social Innovation and Governance in European Cities: Urban Development Between Path Dependency and Radical Innovation. Eur. Urban Reg. Stud. 2007, 14, 195-209. [CrossRef]

70. Berkes, F.; Ross, H. Community Resilience: Toward an Integrated Approach. Soc. Nat. Resour. 2013, 26, 5-20. [CrossRef]

71. Fikret, B.; Carl, F.; Johan, C. Linking Social and Ecological Systems: Management Practices and Social Mechanisms for Building Resilience; Cambridge University Press: Cambridge, UK, 1998.

72. Gunderson, L. Ecological and human community resilience in response to natural disasters. Ecol. Soc. 2010, 15, 29. [CrossRef]

73. Fire, A. Geoforum. Geoforum 2009, 40, 495-496. [CrossRef]

74. Pratt, A.C. City, Culture and Society Resilience, locality and the cultural economy. City, Cult. Soc. 2015, 6, 61-67. [CrossRef]

75. Mela, A.; Mugnano, S.; Davide, O. Territori vulnerabili. Verso una nuova sociologia dei disastri italiana; Franco Angeli: Milano, Italy, 2017.

76. Beel, D.E.; Wallace, C.D.; Webster, G.; Nguyen, H.; Tait, E.; Macleod, M.; Mellish, C. Cultural resilience: The production of rural community heritage, digital archives and the role of volunteers. J. Rural Stud. 2017, 54, 459-468. [CrossRef]

77. Khalili, S.; Harre, M.; Morley, P. Review Article A temporal framework of social resilience indicators of communities to flood, case studies: Wagga wagga and Kempsey, NSW, Australia. Int. J. Disaster Risk Reduct. 2015, 13, 248-254. [CrossRef]

78. Bowenkamp, C. Coordination of mental health and community agencies in disaster response. Int. J. Emerg. Ment. Health 2000, 2, 159-165.

79. Astori, S. Resilienza. Andare oltre: trovare nuove rotte senza farsi spezzare dalle prove della vita; San Paolo Edizioni: Cinisello Balsamo, Italy, 2017.

80. Maria Teresa, F. La comunità nei disastri: una prospettiva psicosociale. Riv. di Psicol. dell'Emergenza e dell'Assistenza Um. 2006, 1, 6-23.

81. Ungar, M. Putting Resilience Theory into Action: Five principles for intervention. Resil. Action 2008, 17, 38.

82. Bogaert, J.; Vranken, I.; Andre, M. Biocultural Landscapes. Biocult. Landsc. Divers. Funct. Values 2014, 89-112. [CrossRef]

83. Xiao, R.; Su, S.; Zhang, Z.; Qi, J.; Jiang, D.; Wu, J. Dynamics of soil sealing and soil landscape patterns under rapid urbanization. CATENA 2013, 109, 1-12. [CrossRef]

84. United Nations. Sendai Framework for Disaster Risk Reduction 2015-2030; United Nations: Sendai, Japan, 2015.

85. UNISDR. Post-2015 Framework for Disaster Risk Reduction (HFA2) Report from 2013 Global Platform Consultations; UNISDR: Geneva, Switzerland, 2013.

86. Choay, F. L'allégorie du patrimoine; Editions du Seuil: Paris, France, 1992.

87. Choay, F. Le Patrimoine en questions Anthologie pour un combat; Seuil: Paris, France, 2009.

88. Babelon, J.-P.; Chastel, A. La notion de patrimoine; Edition Liana Levi: Paris, France, 1994.

89. Berkes, F. Understanding uncertainty and reducing vulnerability: Lessons from resilience thinking. Nat. Hazards 2007, 41, 283-295. [CrossRef]

90. Starzomski, B.M. Book review: Navigating Social-ecological Systems: Building Resilience for Complexity and Change; Cambridge University Press: Cambridge, UK, 2004.

91. Davoudi, S.; Shaw, K.; Haider, L.J.; Quinlan, A.E.; Peterson, G.D.; Wilkinson, C.; Fünfgeld, H.; McEvoy, D.; Porter, L. Resilience: A Bridging Concept or a Dead End? "Reframing" Resilience: Challenges for Planning Theory and Practice Interacting Traps: Resilience Assessment of a Pasture Management System in Northern Afghanistan Urban Resilience: What Does it Mean in Planni. Plan. Theory Pract. 2012, 13, 299-333. [CrossRef]

92. Davoudi, S.; Brooks, E.; Mehmood, A. Evolutionary Resilience and Strategies for Climate Adaptation. Plan. Pract. Res. 2013, 28, 307-322. [CrossRef]

93. Wilkinson, C.; Porter, L.; Colding, J. Metropolitan Planning and Resilience Thinking: A Practitioner 's Perspective. Crit. Plan. 2010, 17, 25-43.

94. UNISDR. EFDRR Survey on Sendai Framework Implementation in Europe; UNISDR: Brussels, Belgium, 2017.

95. René, F. Les pouvoirs publics face aux risques naturels dans l'histoire; CNRS-MSH-Alpes: Grenoble, France, 2002.

96. Gal, R. Social Resilience in Times of Protracted Crises: An Israeli Case Study. Armed Forces Soc. 2014, 40, 452-475. [CrossRef] 
97. Nelson, D.R.; Adger, W.N.; Brown, K. Adaptation to Environmental Change: Contributions of a Resilience Framework. Annu. Rev. Environ. Resour. 2007, 32, 395-419. [CrossRef]

98. Kaczorowska, A.; Kain, J.-H.; Kronenberg, J.; Haase, D. Ecosystem services in urban land use planning: Integration challenges in complex urban settings-Case of Stockholm. Ecosyst. Serv. 2016, 22, $204-212$. [CrossRef]

99. Wilkinson, C.; Saarne, T.; Peterson, G.D.; Colding, J. Strategic spatial planning and the ecosystem services concept an historical exploration. Ecol. Soc. 2013, 18, 37. [CrossRef]

100. Alexander, E.R. Planning rights and their Implications. Plan. Theory 2007, 6, 112-126. [CrossRef]

101. Cortinovis, C.; Geneletti, D. Ecosystem services in urban plans: What is there, and what is still needed for better decisions. Land use policy 2018, 70, 298-312. [CrossRef]

102. Salata, S.; Ronchi, S.; Ghirardelli, F. Ecosystem services supporting landscape planning | I servizi ecosistemici a supporto della pianificazione paesaggistica. Territorio 2016, 77, 45-52. [CrossRef]

103. Stark, D. On Resilience. Soc. Sci. 2014, 3, 60-70. [CrossRef]

104. Alexander, E.R. Evaluations and rationalities: Reasoning with values in planning. In Evaluation in Planning: Evolution and Prospects; Ashgate: Aldershot, UK, 2006; pp. 39-52. ISBN 075464586X.

105. Folke, C.; Carpenter, S.; Elmqvist, T.; Gunderson, L.; CS, H.; Walker, B. Resilience and Sustainable Development: Building Adaptive Capacity in a World of Transformations. Ambio 2002, 31, 437-440. [CrossRef]

(C) 2019 by the authors. Licensee MDPI, Basel, Switzerland. This article is an open access article distributed under the terms and conditions of the Creative Commons Attribution (CC BY) license (http://creativecommons.org/licenses/by/4.0/). 